\title{
Impact of molar-incisor hypomineralization on oral health-related quality of life in schoolchildren
}

\author{
Neusa Barros DANTAS-NETA(a) \\ Lúcia de Fátima Almeida de Deus \\ MOURA $^{(a)}$ \\ Priscila Figueiredo $\mathrm{CRUZ}^{(\mathrm{b})}$ \\ Marcoeli Silva MOURA ${ }^{(a)}$ \\ Saul Martins PAIVA(c) \\ Carolina Castro MARTINS(c) \\ Marina de Deus Moura de LIMA(a)
}

(a) Universidade Federal do Piauí, School of Dentistry, Department of Pathology and Dentistry Clinic, Teresina, PI,Brazil.

(b) Universidade Federal do Piauí, School of Dentistry, Teresina, Pl, Brazil.

(c) Universidade Federal de Minas Gerias, School of Dentistry, Department of Pediatric Dentistry and Orthodontics, Belo Horizonte, MG, Brazil.

Declaration of Interests: The authors certify that they have no commercial or associative interest that represents a conflict of interest in connection with the manuscript.

\section{Corresponding Author:}

Marina de Deus Moura de Lima

E-mail:mdmlima@gmail.com

DOI: 10.1590/1807-3107BOR-2016.vol30.0117

Submitted: Aug 8, 2015

Accepted for publication: July 11, 2016

Last revision: Aug 23, 2016
Abstract: This study evaluated the impact of molar-incisor hypomineralization $(\mathrm{MIH})$ on oral health-related quality of life (OHRQoL) according to the perceptions of schoolchildren and their parents/caregivers. This cross-sectional study consisted of a sample of 594 schoolchildren between 11 and 14 years of age and their parents/caregivers who answered the questionnaires $\mathrm{CPQ}_{11-14} \mathrm{ISF}: 16$ and $\mathrm{P}-\mathrm{CPQ}$, respectively. The main independent variable of this study was MIH of the schoolchildren. Experience of dental caries, malocclusion, and socioeconomic status were treated as confounding variables. Statistical analysis used descriptive analysis and Poisson regression with robust variance. The prevalence of $\mathrm{MIH}$ was $18.9 \%$. The overall $\mathrm{P}-\mathrm{CPQ}$ score ranged from 0 to 35 (average $=7.26 \pm 6.84$ ), and the overall $\mathrm{CPQ}_{11-14} \mathrm{ISF}: 16$ score ranged from 0 to 47 (average $=11.92 \pm 7.98$ ). Severe MIH was associated with a greater negative impact of the "functional limitation" domain $(\mathrm{RR}=1.41 ; 95 \% \mathrm{CI}=1.01-1.97)$, according to parents'/caregivers' perceptions. Severe MIH was associated with a greater negative impact of the "oral symptom" domain $(\mathrm{RR}=1.30 ; 95 \% \mathrm{CI}=1.06-1.60)$ and functional limitation domain $(\mathrm{RR}=1.42 ; 95 \% \mathrm{CI}=1.08-1.86)$, according to the schoolchildren's perceptions. Schoolchildren with severe MIH had a greater negative impact on the oral symptom and functional limitation domains than those without MIH. According to parents'/caregivers' perceptions, schoolchildren with severe MIH had a greater negative impact on the functional limitation domain than those without MIH.

Keywords: Quality of Life; Dental Enamel Hypoplasia; Oral Health; Tooth Demineralization.

\section{Introduction}

Molar-incisor hypomineralization (MIH) is a structural defect of the tooth enamel that affects at least one first permanent molar, and it is often associated with alterations in permanent incisors. ${ }^{1}$ Teeth with MIH present with demarcated opacity with clear and defined limits and can occasionally undergo post-eruptive breakdown. ${ }^{1,2,3,4}$

MIH is associated with many dental problems such as hypersensitivity, quick development of carious lesions, and recurrent dental treatment needs. ${ }^{2,3,5,6,7}$ Such factors can affect the daily lives of individuals, leading to negative social and esthetic effects as well as pain. ${ }^{5}$ Indicators of oral 
health-related quality of life (OHRQoL) are used to determine the impact of oral conditions in the daily lives of individuals. ${ }^{8}$

Several studies have shown that oral conditions affect OHRQoL. ${ }^{910,11,12}$ However, to the best of our knowledge, the impact of MIH on OHRQoL has not been reported. Parents/caregivers should be considered as informants about the oral health of their children as their reports are a good complement to the information obtained from their children. ${ }^{13,14}$

The aim of this study was to evaluate the impact of MIH on OHRQoL according to schoolchildren's and their parents'/caregivers' perceptions.

\section{Methodology}

\section{Ethical considerations}

This study was approved by the Human Research Ethics Committee of the Universidade Federal do Piauí (Protocol 0441.0.045.000-11). An informed consent form was signed by the schoolchildren and the parents/caregivers, in accordance with the Declaration of Helsinki.

\section{Population and study sample}

This was a population-based cross-sectional study of a representative sample of schoolchildren aged 11-14 years from the city of Teresina, Brazil. In 2011, there were 54,056 students in this age group enrolled in Teresina schools. For the sample size calculation, the Epi-info program in StatCalc module was used (version 3.5.2; Centers for Disease Control and Prevention, Atlanta, GA, USA). An MIH prevalence of $19.8 \%$ in children and adolescents aged 6 to 12 years was used. ${ }^{2}$ A correction factor of 1.5 was used to increase accuracy. The confidence interval was $95 \%$, and the standard error was 4.0. The minimum required sample size was 569 students. An additional $20 \%$ of 569 students were included to compensate for possible losses. In total, 683 students and their parents/caregivers were invited to participate in this study.

The sample was proportionally stratified by the type of school. Teresina has $26.1 \%$ private schools and $73.9 \%$ public schools. Each type of school was proportionally stratified by the district of the city (north, south, south-east, east, and central). Three private schools and three public schools from each district were selected by lots. After this draw, classes were randomly drawn from each school, and then, schoolchildren from each class were randomized by random drawing.

The inclusion criterion was a schoolchild who presented with all first permanent molars and permanent incisors fully erupted. Exclusion criteria were children presenting with other types of enamel defects (e.g., moderate/severe dental fluorosis, amelogenesis imperfecta, enamel hypoplasia, enamel tooth malformation linked to syndromes) and children undergoing orthodontic treatment with fixed appliances at the time of evaluation.

\section{Data collection}

Data collection was performed in two stages between April and July 2012. The first stage was performed by the parents/caregivers. They signed the consent form and answered the socioeconomic questionnaire and the Brazilian short form of the Parental-Caregivers' Perceptions Questionnaire (P-CPQ). ${ }^{14}$ The second stage was performed by the schoolchildren whose parents/caregivers consented to study participation. They were directed to answer the self-reported 16-item Child Perception Questionnaire $\left(\mathrm{CPQ}_{11-14} \mathrm{ISF}: 16\right)^{15}$ and were clinically assessed.

\section{Non-clinical data collection}

Three questionnaires were used: (a) a questionnaire addressing sociodemographic condition, (b) the short form of the Brazilian P-CPQ for parents/caregivers, ${ }^{14}$ and (c) the Brazilian $\mathrm{CPQ}_{11-14}$ ISF:16 for children. ${ }^{15}$ The first and second questionnaires were completed by the parents/caregivers. The first questionnaire contained information about sociodemographic factors: gender, age, type of school (public or private), family income (categorized based on the Brazilian monthly minimum wage: an amount equivalent to USD \$290.38), mother's schooling (years of formal study), family structure (nuclear structure for schoolchildren who lived with both parents and non-nuclear structure for schoolchildren living with only one parent or neither). The third questionnaire was self-completed by the children.

The short form of P-CPQ contained children's issues during the last 3 months and was divided into three 
domains: "oral symptom," "functional limitation," and "well-being." The items were answered on a five-point rating scale: "never" $=0$, "once or twice" $=1$, "sometimes" = 2, "often" = 3, and "every day or almost every day" $=4$. "Don't know" responses were permitted and scored as 0 . The total score ranged from 0 to 52. The higher the score, the higher was the impact of oral health on QoL of the children. ${ }^{14}$

The Brazilian version of the questionnaire $\mathrm{CPQ}_{11-14} \mathrm{ISF}: 16$ consisted of 16 items divided into four areas: "oral symptom," "functional limitation," "emotional well-being," and "social well-being." Each item addressed the frequency of events in the previous 3 months. A five-point rating scale was used, with the following options: "never" $=0$, "once/twice" $=1$, "sometimes" $=2$, "often" $=3$, and "every day/almost every day" $=4$. The total score ranged from 0 to 64 , and higher scores denoted a more negative impact of oral conditions on QoL. ${ }^{15}$

\section{Clinical data collection}

The schoolchildren were examined by a single examiner, previously calibrated within a classroom. Before the clinical examinations, supervised tooth-brushing was performed. The schoolchildren sat on a chair and leaned back, resting the back of their heads on the examiner's lap. A dental mirror (Duflex, SS White, Rio de Janeiro, Brazil), periodontal probe (WHO-621, Trinity, Campo Mourão, Brazil), and gauze swab were used under artificial lighting (desk lamp model Pelican, Startec127V, São Paulo, Brazil) for the dental examination. All the teeth were examined dry by a gauze swab.

Schoolchildren were diagnosed with MIH when at least one first permanent molar was affected, with or without the involvement of the incisors, according to the criteria proposed by the European Academy of Paediatric Dentistry (EAPD). ${ }^{1}$ The diagnostic criteria for MIH were at least one of the first permanent molars affected by (a) well-demarcated opacities greater than $1 \mathrm{~mm}$; (b) post-eruptive enamel breakdown; (c) atypical restorations, when there is the presence of opacity in the margins; and (d) absence of first permanent molars in dentitions with low caries activity associated with one of the other previously mentioned factors. ${ }^{1,2}$
The severity of MIH was classified as mild (demarcated opacities without fracture), moderate (hard and fractured enamel and need for treatment), or severe (loss of tooth structure affecting the enamel and dentine, replacement of hard tissues with atypical restorations, and tooth extraction due to hypomineralization). ${ }^{2,16,17,18}$ Each schoolchild's MIH severity was defined by the most severe defect observed in the permanent first molars or permanent incisors.

Differential diagnoses between $\mathrm{MIH}$ and fluorosis and amelogenesis imperfecta and enamel hypoplasia were performed. Teeth with MIH have demarcated opacities and are prone to caries, unlike teeth with fluorosis, which have diffuse opacities. ${ }^{19,20}$ Fluorosis should lead to similar alterations in homologous teeth, a horizontal striated pattern across the teeth, brown stains often altering the anatomy of the teeth or areas with pits or wear, scattered brown spots, and corrosive-looking teeth. ${ }^{19,20}$ In amelogenesis imperfecta, changes in the structure and appearance of the enamel should be present in all or almost all the deciduous and permanent teeth. There is often a history of family onset. ${ }^{20}$ In enamel hypoplasia, the borders of the normal enamel are smooth, while in post-eruptive enamel breakdown, the borders of the normal enamel are irregular. ${ }^{20}$

Schoolchildren were also evaluated to determine their experience of caries and malocclusion because they were considered confounding variables. The experience of caries was diagnosed through the criteria of the World Health Organization. The presence or absence of dental caries was evaluated according to the DMFT index [decayed permanent teeth (D), missing (M), and filled (F)]. ${ }^{19}$ DMFT values $\geq 1$ were considered as indicating the presence of dental caries. Malocclusion was characterized by the presence of any of the following abnormalities: deep overbite, increased overjet, anterior open bite, anterior crossbite, and posterior crossbite. ${ }^{21}$

\section{Calibration exercise}

Prior to the commencement of the study, one of the authors underwent a series of calibration exercises. The calibration exercise was performed in two stages. The first stage included a theoretical discussion about 
the clinical diagnosis and severity of $\mathrm{MIH}$, dental caries, and malocclusion. Furthermore, oral clinical examination training using slides was performed. ${ }^{2,19,21}$

The second stage was the clinical examination. Twenty schoolchildren who did not participate in the main study were examined and re-examined after 15 days. ${ }^{19}$ All conditions of the schoolchildren were evaluated. Intra-examiner reliability was determined on a tooth-by-tooth basis for each clinical condition. Cohen's kappa coefficient for intra-examiner calibration was $0.91,0.70$, and 0.88 for $\mathrm{MIH}$, malocclusion, and dental caries, respectively.

\section{Pilot study}

A pilot study was conducted to evaluate the methodology, dental examination, and administration of the questionnaires. Twenty schoolchildren who did not participate in the main study were selected by convenience sampling. The pilot study confirmed the original study design, and we had no modifications in the approach.

\section{Statistical analysis}

Data processing and statistical analysis were performed using the Statistical Package for Social Sciences version 20.0 for Windows (SPSS Inc., Chicago, IL, USA). The outcome variables were overall P-CPQ and $\mathrm{CPQ}_{11-14}$ ISF:16 and their specific domains. These were applied as count variables. Caries, malocclusion, and socioeconomic factors were applied as confounding variables.

Poisson regression analysis with robust variance was used for multivariate analysis, as in previous studies. ${ }^{22}$ Overall P-CPQ and $\mathrm{CPQ}_{11-14} \mathrm{ISF}: 16$ and specific domain scores were compared in terms of the rate ratios (RRs) and respective 95\% confidence intervals (95\% CIs) with interest and confounding variables. To be entered into the final model, variables with $p \leq 0.20$ and epidemiological variables that justified the study (severity of MIH) were used. The final model contained only factors that remained associated at the $\mathrm{p} \leq 0.05$ level.

\section{Results}

In total, 629 (response rate $=92.1 \%$ ) parents/caregivers authorized their children to participate in the study and answer all questions. However, 11 schoolchildren (1.6\%) were excluded because they met the exclusion criteria and $24(3.5 \%)$ were excluded because they were absent from class on the day of the clinical examination. Therefore, in total, 594 (86.9\%) schoolchildren and their parents/caregivers were enrolled in this study: $154(22.5 \%)$ from private schools and 440 (64.4\%) from public schools.

The mean age of the adolescents was 12.45 years $(\mathrm{SD}=1.11)$. The predominant household income was lower than or equal to one minimum wage $(55.2 \%)$, $360(60.6 \%)$ children belonged to a nuclear family structure, and $276(46.5 \%)$ children had parents who had studied for 8-11 years. Most parental questionnaires were answered by mothers (90\%).

Clinical examination revealed that the prevalence of MIH was $18.4 \%(n=109)$ in schoolchildren aged 11-14 years. The prevalence of MIH in the public schools was $19.3 \%$ and that in private schools was $15.6 \%$. With regard to the severity of MIH, 54 (49.5\%) schoolchildren presented with mild, $30(27.5 \%)$ moderate, and $25(23.0 \%)$ severe $\mathrm{MIH}$. It was revealed that $301(50.7 \%)$ schoolchildren had malocclusion and $302(50.8 \%)$ had dental caries. The mean DMFT was $1.49(\mathrm{SD}=0.50)$.

In total, 501 (84.3\%) parents/caregivers reported an overall $\mathrm{P}-\mathrm{CPQ}$ of $\geq 1$. The highest score for overall P-CPQ was 35 points. In total, 583 (98.1\%) schoolchildren reported an overall $\mathrm{CPQ}_{11-14}$ ISF:16 of $\geq 1$. The highest score for overall $\mathrm{CPQ}_{11-14} \mathrm{ISF}: 16$ was 47 points (Table 1 ).

The final model revealed that according to parents'/caregivers' perceptions, schoolchildren with severe MIH had a $41 \%$ higher rate of impact than those without MIH in the functional limitation domain of $\mathrm{P}-\mathrm{CPQ}(\mathrm{RR}=1.41 ; 95 \% \mathrm{CI}=1.01,1.97)$ (Table 2$)$.

Schoolchildren with severe MIH had 30\% and $42 \%$ higher rates of impact than those without $\mathrm{MIH}$ in the oral symptom $(\mathrm{RR}=1.30 ; 95 \% \mathrm{CI}=1.06,1.60)$ and functional limitation $(\mathrm{RR}=1.42 ; 95 \% \mathrm{CI}=1.08$, 1.86) domains of $C P Q_{11-14} I S F: 16$, respectively (Table 3).

\section{Discussion}

To the best of our knowledge, this is one of the first studies to analyze the association between MIH and OHRQoL. It was concluded that schoolchildren with 
Table 1. Mean overall and specific subscale scores of the P-CPQ and $C P Q_{11-14} I S F: 16$ questionnaires $(n=594)$.

\begin{tabular}{|c|c|c|c|c|c|c|c|}
\hline \multirow{2}{*}{ Variables } & \multirow{2}{*}{ Mean (SD) } & \multirow{2}{*}{ Median } & \multirow{2}{*}{ Minimum } & \multirow{2}{*}{ Maximum } & \multicolumn{3}{|c|}{ Percentages } \\
\hline & & & & & $25 \%$ & $50 \%$ & $75 \%$ \\
\hline \multicolumn{8}{|l|}{$\mathrm{P}-\mathrm{CPQ}$} \\
\hline Oral symptoms & $1.86(2.00)$ & 1.0 & 0 & 10 & 0 & 1 & 3 \\
\hline Functional limitation & $2.67(2.76)$ & 2.0 & 0 & 14 & 0 & 2 & 4 \\
\hline Well-being & $2.75(3.67)$ & 2.0 & 0 & 19 & 0 & 2 & 4 \\
\hline Overall B-P-CPQ & $7.26(6.84)$ & 5.0 & 0 & 35 & 2 & 5 & 11 \\
\hline \multicolumn{8}{|l|}{$C P Q_{11-14} I S F: 16$} \\
\hline Oral symptoms & $4.08(2.40)$ & 4.0 & 0 & 13 & 2 & 4 & 6 \\
\hline Functional limitation & $3.36(2.76)$ & 3.0 & 0 & 13 & 1 & 3 & 5 \\
\hline Emotional well-being & $2.52(2.76)$ & 2.0 & 0 & 12 & 0 & 2 & 4 \\
\hline Social well-being & $1.95(2.31)$ & 1.0 & 0 & 16 & 0 & 1 & 3 \\
\hline Overall CPQ ${ }_{11-14} \mathrm{ISF}: 16$ & 11.92 (7.98) & 10.0 & 0 & 47 & 6 & 10 & 17 \\
\hline
\end{tabular}

severe MIH are associated with a lower impact on the oral symptom and functional limitation domains of OHRQoL than those without MIH.

There is scarcity of literature about the prevalence of the negative impact of MIH on OHRQoL. Thus, for sample size calculation, the prevalence of MIH in a Brazilian study with a representative sample was used..$^{2}$ The study used a population-based sample of adolescents aged 11-14 years and their families, enabling the data to be extrapolated to the general population.

The prevalence of MIH in this study was confirmed by the results of another Brazilian study that also had a predominance of mild defects. ${ }^{2}$ Previous studies have addressed the prevalence and severity of MIH in children and adolescents. ${ }^{2,18,23,24,25}$ These studies have associated MIH with cosmetic changes caused by the presence of demarcated opacities in the incisors or pain caused by dentine hypersensitivity. $3,16,18,27$

Some authors have compared different age groups and found that older children have more severe $\mathrm{MIH}$ than younger children because of the post-eruptive damage to the hypomineralised enamel. ${ }^{2,27,28}$ Therefore, this study included schoolchildren aged 11-14 years to check whether there were severe MIH impacts on OHRQoL.

Schoolchildren with severe MIH were associated with lower OHRQoL than those without MIH in the oral symptom and functional limitation domains. The impact found is plausible because MIH may cause oral symptoms such as esthetic alterations, dental pain/discomfort, bad breath, and food impaction. 3,16,26 Moreover, it may cause functional limitations such as difficulty in biting or chewing food, trouble in sleeping, and difficulty in drinking or eating hot or cold beverages and foods. ${ }^{3,16,26}$

Teeth with MIH can suffer from enamel breakdown after eruption and occlusal contacts depending on the degree of enamel porosity. This enamel breakdown facilitates food impaction. The enamel loss can lead to the development of dentine hypersensitivity caused by the exposure of the dentinal tubules, which are broader in these teeth. ${ }^{2,16,26}$ Thus, the individual neglects oral hygiene, which in turn leads to biofilm accumulation, increasing the chances of developing tooth decay. $2,3,16,26$

We included dental caries, malocclusion, and socioeconomic factors as confounding variables because some studies have shown that these variables can be associated with worse OHRQoL. 9,10,29,30,31,32,33,34,35

Studies have shown that dental caries has a negative impact on OHRQoL. ${ }^{10,30,36}$ Severe dental caries usually produces an unsightly appearance. ${ }^{30}$ Therefore, parents/caregivers of schoolchildren with dental caries reported that their children had a $27 \%$ greater probability of a one-point increase in the well-being score. 
Impact of molar-incisor hypomineralization on oral health-related quality of life in schoolchildren

Table 2. Association between scores of the P-CPQ questionnaire with $\mathrm{MIH}$ and confounding variables: final multivariate model $(n=594)$.

\begin{tabular}{|c|c|c|c|c|c|}
\hline \multirow[t]{2}{*}{ Variable } & & Oral symptoms & $\begin{array}{l}\text { Functional } \\
\text { limitation }\end{array}$ & Well-being & Total score \\
\hline & & \multicolumn{4}{|c|}{$\mathrm{RR}_{\text {adj. }}^{1}(95 \% \mathrm{Cl})$} \\
\hline \multirow{7}{*}{$\mathrm{MIH}$} & & 1.34 & 1.41 & 1.03 & 1.15 \\
\hline & Severe & $(0.95-1.88)$ & $(1.01-1.97)$ & $(0.68-1.56)$ & $(0.87-1.53)$ \\
\hline & & 1.25 & 1.27 & 1.16 & 1.19 \\
\hline & Moderate & $(0.87-1.77)$ & $(0.86-1.87)$ & $(0.75-1.80)$ & $(0.85-1.66)$ \\
\hline & & 0.99 & 0.99 & 0.91 & 0.95 \\
\hline & Milla & $(0.77-1.29)$ & $(0.72-1.35)$ & $(0.61-1.35)$ & $(0.73-1.24)$ \\
\hline & No & 1 & 1 & 1 & 1 \\
\hline \multirow{3}{*}{ Dental caries } & & 1.18 & & 1.27 & 1.20 \\
\hline & Yes & $(0.99-1.41)$ & - & $(1.01-1.58)$ & $(1.03-1.41)$ \\
\hline & No & 1 & - & 1 & 1 \\
\hline \multirow{3}{*}{ Malocclusion } & & & & 1.47 & 1.23 \\
\hline & Yes & - & - & $(1.20-1.81)$ & $(1.06-1.43)$ \\
\hline & No & & & 1 & 1 \\
\hline \multirow{3}{*}{ Type of school } & & 1.03 & & 2.10 & 1.49 \\
\hline & Public & $(0.79-1.34)$ & - & $(1.56-2.84)$ & $(1.23-1.80)$ \\
\hline & Private & 1 & - & 1 & 1 \\
\hline \multirow{3}{*}{$\begin{array}{l}\text { Family income } \\
\text { (minimum wage, MW) }\end{array}$} & & 1,29 & 1.18 & & \\
\hline & $\leq 1 \mathrm{MW}$ & $(1,05-1,58)$ & $(0.98-1.41)$ & - & - \\
\hline & $>1 \mathrm{MW}$ & 1 & 1 & - & - \\
\hline \multirow{5}{*}{ Mother's schooling } & -8 urare & 1.47 & 1.16 & & \\
\hline & $<$ o years & $(1.12-1.94)$ & $(0.98-1.41)$ & & - \\
\hline & 8-1] veare & 1.23 & 0.99 & & \\
\hline & $0-11$ years & $(0.93-1.62)$ & $(0.79-1.27)$ & - & - \\
\hline & $>11$ years & 1 & 1 & - & - \\
\hline \multirow[t]{2}{*}{ Gender } & Female & $\begin{array}{c}1.28 \\
(1,07-1,54)\end{array}$ & $\begin{array}{c}1.09 \\
(0.92-1.29)\end{array}$ & - & - \\
\hline & Male & 1 & 1 & - & - \\
\hline
\end{tabular}

'Rate ratios adjusted.

Malocclusion was associated with a lower OHRQoL, according to the schoolchildren and their parents/caregivers. This result was in agreement with that reported in the literature. ${ }^{10,31,32}$ The emotional well-being domains addressed in the questions were concerned with feelings about oneself and others' perception. ${ }^{14,15}$ The social well-being domain addressed in the questions was concerned with difficulty in school and in activities, avoidance of smiling, and difficulties in relationships with other children. ${ }^{14,15}$

Disturbances in normal occlusion can reduce social acceptance and lead to low self-esteem in adolescents. ${ }^{11,31}$ Theoretical explanations of this relationship are based on adolescents' dissatisfaction on a daily basis with self-image, esthetics, difficulty in chewing, and speech difficulties caused by 
Table 3. Association between scores of the CPQ ${ }_{11-14}$ ISF: 16 questionnaire with $\mathrm{MIH}$ and confounding variables: final multivariate model $(\mathrm{n}=594)$.

\begin{tabular}{|c|c|c|c|c|c|c|}
\hline \multirow[t]{2}{*}{ Variable } & & Oral symptoms & $\begin{array}{l}\text { Functional } \\
\text { limitation }\end{array}$ & $\begin{array}{l}\text { Emotional } \\
\text { well-being }\end{array}$ & Social well-being & Total score \\
\hline & & \multicolumn{3}{|c|}{$\operatorname{RR}^{1}{ }_{\text {adi }}(95 \% \mathrm{Cl})$} & & \\
\hline \multirow{7}{*}{$\mathrm{MIH}$} & \multirow{2}{*}{ Severe } & 1.30 & 1.42 & 0.91 & 0.80 & 1.09 \\
\hline & & $(1.06-1.60)$ & $(1.08-1.86)$ & $(0.60-1.39)$ & $(0.54-1.19)$ & $(0.87-1.37)$ \\
\hline & \multirow{2}{*}{ Moderate } & 1.19 & 1.24 & 0.99 & 1.11 & 1.12 \\
\hline & & $(0.97-1.45)$ & $(0.91-1.68)$ & $(0.70-1.42)$ & $(0.76-1.65)$ & $(0.89-1.41)$ \\
\hline & \multirow{2}{*}{ Mild } & 0.98 & 0.96 & 0.95 & 0.96 & 0.97 \\
\hline & & $(0.80-1.18)$ & $(0.77-1.20)$ & (0.70-1.29) & $(0.70-1.32)$ & $(0.80-1.18)$ \\
\hline & No & 1 & 1 & 1 & 1 & 1 \\
\hline \multirow{3}{*}{ Dental caries } & & & & 1.19 & & 1.10 \\
\hline & Yes & - & - & $(0.99-1.42)$ & - & (0.99-1.23) \\
\hline & No & - & - & 1 & - & 1 \\
\hline \multirow{3}{*}{ Malocclusion } & & & & 1.36 & 1.40 & 1.18 \\
\hline & Yes & - & - & $(1.14-1.61)$ & $(1.17-1.69)$ & $(1.06-1.31)$ \\
\hline & No & - & - & 1 & 1 & 1 \\
\hline \multirow{3}{*}{ Type of school } & & 1.14 & 1.23 & 1.51 & 1.53 & 1.31 \\
\hline & PUDIIC & $(1.02-1.27)$ & (1.04-1.45) & (1.20-1.92) & $(1.12-2.09)$ & (1.15-1.49) \\
\hline & Private & 1 & 1 & 1 & 1 & 1 \\
\hline \multirow{3}{*}{$\begin{array}{l}\text { Family income } \\
\text { (minimum wage - } \\
\text { MW) }\end{array}$} & & & & & 1.27 & \\
\hline & $\leq \mathrm{IMW}$ & - & - & - & $(1.01-1.61)$ & - \\
\hline & $>1 \mathrm{MW}$ & - & - & - & 1 & - \\
\hline \multirow{3}{*}{ Family Structure } & & 1.14 & 1.20 & & 1.21 & 1.17 \\
\hline & Non-nuclear & $(1.03-1.25)$ & (1.05-1.37) & - & $(1.01-1.47)$ & (1.05-1.30) \\
\hline & Nuclear & 1 & 1 & - & 1 & 1 \\
\hline \multirow{3}{*}{ Gender } & & 1.04 & 1.25 & & & \\
\hline & remale & $(0.94-1.15)$ & (1.09-1.43) & - & - & - \\
\hline & Male & 1 & 1 & - & - & - \\
\hline
\end{tabular}

'Rate ratios adjusted.

malocclusion. ${ }^{11,31}$ This may happen because malocclusion causes esthetic features that can induce adverse social responses among teenagers, such as nicknames generated by schoolmates. ${ }^{31}$

Schoolchildren from public schools had a lower OHRQoL than those from private schools. Parents/caregivers of schoolchildren who earned less than or equal to one minimum wage and mothers who had less than 8 years of education reported that their children had a lower OHRQoL. These results support the results of previous studies that socioeconomic status is associated with different oral conditions and OHRQoLs. ${ }^{911,29,31}$ The low educational level may lead to a reduced income, unemployment, and low professional positions. ${ }^{29}$ These conditions influence health habits and self-rated oral health ${ }^{24}$ due to the difficulty in accessing information, dental services, oral hygiene products, and private schools. ${ }^{33}$ 
A non-nuclear family structure is also associated with a lower OHRQoL. This result can be explained by the influence of the home environment on schoolchildren's oral health behavior. ${ }^{9}$ Studies have shown that schoolchildren who belong to a non-nuclear family structure have worse oral health behaviors because they tend to brush their teeth less often and have fewer annual visits to dentists. ${ }^{34,35}$

Female schoolchildren had higher oral symptom and functional limitation scores than male schoolchildren. The association between gender and P-CPQ and $\mathrm{CPQ}_{11,12,13,14}$ ISF:16 scores may be explained by a higher concern by girls in relation to functional and esthetic-related health issues, as observed in another study. ${ }^{29}$

The present study had limitations inherent in cross-sectional studies because the data were related to perceptions of the moment in which the individual lived. Thus, longitudinal studies are required to enable a better understanding of the effects of $\mathrm{MIH}$ on OHRQoL.

It is necessary to train dentists for the early detection and care of MIH. Early identification of MIH can avoid the increased severity of these problems and reduce the impact on OHRQoL in schoolchildren.

\section{Conclusion}

The following conclusions can be drawn on the basis of the findings of this investigation:

1. Schoolchildren with severe MIH have a greater negative impact on the oral symptom and functional limitation domains than those without $\mathrm{MIH}$.

2. Schoolchildren with severe MIH have a greater negative impact on the functional limitation domain than those without $\mathrm{MIH}$, according to parents'/caregivers' perceptions.

\section{Acknowledgments}

This study was supported by the State of Piaui Research Foundation (FAPEPI) and the Coordination for the Improvement of Higher Education Personnel (CAPES), Brazil. The authors thank the graduate students in dentistry at the Federal University of Piauí, André Souza Aguiar and Guilherme Castro Lima Silva do Amaral, for assisting as annotators during the data collection.

\section{References}

1. Weerheijm KL, Duggal M, Mejàre I, Papagiannoulis L, Koch G, Martens LC et al. Judgement criteria for molar incisor hy pomineralisation (MIH) in epidemiologic studies: a summary of the European meeting on MIH held in Athens, 2003. Eur J Paediatr Dent. 2003;4(3):110-3.

2. Costa-Silva CM, Jeremias F, Souza JF, Cordeiro

RC, Santos-Pinto L, Zuanon AC. Molar incisor hypomineralization: prevalence, severity and clinical consequences in Brazilian children. Int J Paediatr Dent. 2010;20(6):426-34. doi:10.1111/j.1365-263X.2010.01097.x

3. Lygidakis NA. Treatment modalities in children with teeth affected by molar-incisor enamel hypomineralisation (MIH): a systematic review. Eur Arch Paediatr Dent. 2010;11(2):65-74. doi:10.1007/BF03262715

4. Farah RA, Swain MV, Drummond BK, Cook R, Atieh M. Mineral density of hypomineralised enamel. J Dent. 2010;38(1):50-8. doi:10.1016/j.jdent.2009.09.002

5. Jälevik B, Klingberg G. Treatment outcomes and dental anxiety in 18-year-olds with $\mathrm{MIH}$, comparisons with healthy controls: a longitudinal study. Int J Paediatr Dent. 2012;22(2):85-91. doi:10.1111/j.1365-263X.2011.01161.x

6. Jälevik B, Klingberg GA. Dental treatment, dental fear and behaviour management problems in children with severe enamel hypomineralization of their permanent first molars. Int J Paediatr Dent. 2002;12(1):24-32. doi:10.1046/j.0960-7439.2001.00318.x

7. Pitiphat W, Savisit R, Chansamak N, Subarnbhesaj A. Molar incisor hypomineralization and dental caries in six- to seven-year-old Thai children. Pediatr Dent. 2014;36(7):478-82.

8. Locker D, Allen F. What do measures of "oral health-related quality of life" measure? Community Dent Oral Epidemiol. 2007;35(6):401-11. doi:10.1111/j.1600-0528.2007.00418.x

9. Paula JS, Leite IC, Almeida AB, Ambrosano GM, Mialhe FL. The impact of socioenvironmental characteristics on domains of oral health-related quality of life in Brazilian schoolchildren. BMC Oral Health. 2013;13(1):10. doi:10.1186/1472-6831-13-10

10. Foster Page LA, Thomson WM, Ukra A, Baker SR. Clinical status in adolescents: is its impact on oral health-related quality of life influenced by psychological characteristics? Eur J Oral Sci. 2013;121(3 Pt 1):182-7. doi:10.1111/eos.12034 
11. Scapini A, Feldens CA, Ardenghi TM, Kramer PF. Malocclusion impacts adolescents' oral health-related quality of life. Angle Orthod. 2013;83(3):512-8. doi:10.2319/062012-509.1

12. Severo Alves L, Dam-Teixeira N, Susin C, Maltz M. Association among quality of life, dental caries treatment and intraoral distribution in 12-year-old South Brazilian schoolchildren. Community Dent Oral Epidemiol. 2013;41(1):22-9. doi:10.1111/j.1600-0528.2012.00707.x

13. Weyant RJ, Manz M, Corby P, Rustveld L, Close J. Factors associated with parents' and adolescents' perceptions of oral health and need for dental treatment. Community Dent Oral Epidemiol. 2007;35(5):321-30. doi:10.1111/j.1600-0528.2006.00336.x

14. Goursand D, Ferreira MC, Pordeus IA, Mingoti SA, Veiga RT, Paiva SM. Development of a short form of the Brazilian Parental-Caregiver Perceptions Questionnaire using exploratory and confirmatory factor analysis. Qual Life Res. 2013;22(2):393-402. doi:10.1007/s11136-012-0145-3

15. Torres CS, Paiva SM, Vale MP, Pordeus IA, Ramos-Jorge ML, Oliveira AC et al. Psychometric properties of the Brazilian version of the Child Perceptions Questionnaire (CPQ11-14): short forms. Health Qual Life Outcomes. 2009;7(1):43. doi:10.1186/1477-7525-7-43

16. Leppäniemi A, Lukinmaa PL, Alaluusua S. Nonfluoride hypomineralizations in the permanent first molars and their impact on the treatment need. Caries Res. 2001;35(1):36-40. doi:10.1159/000047428

17. Ghanim A, Bagheri R, Golkari A, Manton D. Molar-incisor hypomineralisation: a prevalence study amongst primary schoolchildren of Shiraz, Iran. Eur Arch Paediatr Dent. 2014 Apr;15(2):75-82. doi:10.1007/s40368-013-0067-y

18. Oyedele TA, Folayan MO, Adekoya-Sofowora CA, Oziegbe EO. Co-morbidities associated with molarincisor hypomineralisation in 8 to 16 year old pupils in Ile-Ife, Nigeria. BMC Oral Health. 2015;15:37. doi:10.1186/s12903-015-0017-7

19. World Health Organization - WHO. Oral health surveys, basics methods. 5th ed. Geneva: World Health Organization; 2013.

20. Weerheijm KL. Molar incisor hypomineralization (MIH): clinical presentation, aetiology and management. Dent Update. 2004;31(1):9-12.

21. Grabowski R, Stahl F, Gaebel M, Kundt G. Relationship between occlusal findings and orofacial myofunctional status in primary and mixed dentition. Part I: prevalence of malocclusions. J Orofac Orthop. 2007;68(1):26-37. doi:10.1007/s00056-007-1606-0

22. Bendo CB, Paiva SM, Abreu MH, Figueiredo LD, Vale MP. Impact of traumatic dental injuries among adolescents on family's quality of life: a population-based study. Int J Paediatr Dent. 2014;24(5):387-96. doi:10.1111/ipd.12083
23. Cho SY, Ki Y, Chu V. Molar incisor hypomineralization in Hong Kong Chinese children. Int J Paediatr Dent. 2008;18(5):348-52. doi:10.1111/j.1365-263X.2008.00927.x

24. Li L, Li J. [Investigation of molar-incisor hypomineralization among children from 6 to 11 years in Lucheng district, Wenzhou city]. Shanghai Kou Qiang Yi Xue. 2012;21(5):576-9. Chinese.

25. Oyedele TA, Folayan MO, Adekoya-Sofowora CA, Oziegbe EO, Esan TA. Prevalence, pattern and severity of molar incisor hypomineralisation in 8- to 10-year-old school children in Ile-Ife, Nigeria. Eur Arch Paediatr Dent. 2015;16(3):277-82. doi:10.1007/s40368-015-0175-y

26. Fagrell TG, Lingström P, Olsson S, Steiniger F, Norén JG. Bacterial invasion of dentinal tubules beneath apparently intact but hypomineralized enamel in molar teeth with molar incisor hypomineralization. Int J Paediatr Dent. 2008;18(5):33340. doi:10.1111/j.1365-263X.2007.00908.x

27. Ghanim A, Morgan M, Mariño R, Bailey D, Manton D. Molar-incisor hypomineralisation: prevalence and defect characteristics in Iraqi children. Int J Paediatr Dent. 2011;21:413-21. doi:10.1111/j.1365-263X.2011.01143.x

28. Martínez Gómez TP, Guinot Jimeno F, Bellet Dalmau LJ, Giner Tarrida L. Prevalence of molarincisor hypomineralisation observed using transillumination in a group of children from Barcelona (Spain). Int J Paediatr Dent. 2012;22(2):100-9. doi:10.1111/j.1365-263X.2011.01172.x

29. Piovesan C, Antunes JL, Guedes RS, Ardenghi TM. Impact of socioeconomic and clinical factors on child oral health-related quality of life (COHRQoL). Qual Life Res. 2010;19(9):1359-66. doi:10.1007/s11136-010-9692-7

30. Abanto J, Paiva SM, Raggio DP, Celiberti P, Aldrigui JM, Bönecker M. The impact of dental caries and trauma in children on family quality of life. Community Dent Oral Epidemiol. 2012;40(4):323-31. doi:10.1111/j.1600-0528.2012.00672.x

31. Sardenberg F, Martins MT, Bendo CB, Pordeus IA, Paiva SM, Auad SM et al. Malocclusion and oral health-related quality of life in Brazilian school children. Angle Orthod. 2013;83(1):83-9. doi:10.2319/010912-20.1

32. Foster Page LA, Thomson WM, Jokovic A, Locker D. Validation of the Child Perceptions Questionnaire (CPQ 11-14). J Dent Res. 2005;84(7):649-52. doi:10.1177/154405910508400713

33. Renzaho AM, Silva-Sanigorski A. The importance of family functioning, mental health and social and emotional well-being on child oral health. Child Care Health Dev. 2014;40(4):543-52. doi:10.1111/cch.12053

34. Jung SH, Tsakos G, Sheiham A, Ryu JI, Watt RG. Socio-economic status and oral health-related behaviours in Korean adolescents. Soc Sci Med. 2010;70(11):1780-8. doi:10.1016/j.socscimed.2010.02.022 
Impact of molar-incisor hypomineralization on oral health-related quality of life in schoolchildren

35. Levin KA, Currie C. Adolescent toothbrushing and the home environment: sociodemographic factors, family relationships and mealtime routines and disorganisation. Community Dent Oral Epidemiol. 2010;38(1):10-8. doi:10.1111/j.1600-0528.2009.00509.x
36. Albites U, Abanto J, Bönecker M, Paiva SM, Aguilar-Gálvez D, Castillo JL. Parental-caregiver perceptions of child oral health-related quality of life (P-CPQ): psychometric properties for the peruvian spanish language. Med Oral Patol Oral Cir Bucal. 2014;19(3):e220-4. doi:10.4317/medoral.19195 